\title{
The Impact of Glossed Texts on Reading Comprehension among Tertiary Saudi Students
}

\author{
Bader Alharbi ${ }^{1}$ \\ ${ }^{1}$ Department of English, College of Science and Art in Ar Ras, Qassim University \\ Correspondence: Department of English, College of Science and Art in Ar Ras, Qassim University. E-mail: \\ bihrbie@qu.edu.sa
}

Received: November 4, 2017

Accepted: February 20, 2018 Online Published: February 23, 2018

doi: $10.5539 /$ elt.v11n3p153

URL: http://doi.org/10.5539/elt.v11n3p153

\begin{abstract}
The purpose of this study is to explore the existing effect of gloss conditions on reading comprehension and vocabulary understanding of learners in the context of English as a foreign language. The study composed of 72 male students aged between 19 and 21 years selected from Qassim University in Saudi Arabia. The participants were divided into four groups, namely; L1 Arabic gloss, L2 English gloss, a combination of L1 and L2, and the last group with no gloss. Results and findings of the study revealed a significant difference regarding the comprehension of the texts among the experimental groups when correlated with the control group. Additionally, there was no significant change noted regarding performance among the experimental groups. Another finding indicated that the learners had a preference of L1 and L2 gloss over L1 gloss and L2 gloss types, with $93.03 \%$ of them preferring to read glossed texts. Overall, these findings suggest that the gloss and no conditions were significantly distinct. This research results will be beneficial for future studies that are interested in developing reading comprehension of EFL learners.
\end{abstract}

Keywords: textual glosses, tertiary EFL Learners, reading comprehension, Arabic glosses, vocabulary gloss

\section{Introduction}

\subsection{Introduction to the Problem}

Vocabulary knowledge and development is crucial to increase the reading comprehension. Ali and Ayub (2012) believe that reading comprehension is difficult to happen without an understanding of the passage words. According to Nagy (1988), it is very challenging to understand a text without being familiar with most of its words. Therefore, many researchers attempted to suggest some strategies that can facilitate learners to deal with new words and accelerate their reading comprehension. One of the strategies is using vocabulary glossing which may lead to increase in the reading comprehension (Palmer, Boon, \& Spencer, 2014). Jung (2016) defines glossing as the "information provided about an unfamiliar linguistic item in the form of a definition, synonym, or translation to reduce the linguistic obscurity, and in so doing, assist reading comprehension" (p. 93). Many studies have been conducted to identify the significance of glossing in reading and vocabulary learning. The results of these studies have provided mixed results with some indicating that glossing enhances reading comprehension and vocabulary learning (Tseng, Yeh, \&Yang, 2015), while others stating that glossing does not have any impact on learners (H. Lee \& J. H. Lee, 2015).

In the recent past, attention has been eased from the implication of glossing having positive results on the issue of reading comprehension and vocabulary learning to the comprehensive understanding of the types of glossing. Additionally, the issue of the effectiveness of L1 and L2 has also been dragged into the debate. Nevertheless, the results and findings of these studies contradict the notion of having native language L1 and the subsequent glossing conducted with the L2. As such, this exacerbates the debate of reading comprehension as far as glossing is concerned (Taylor, 2002). Thus, conflicting results have been reported in the relevant literature about the influences of using glosses on reading comprehension and the most preferred type of glosses by Saudi learners. Therefore, this study aims at addressing these concerns by raising the following research questions:

1). What influence do different textual glosses have on reading comprehension of groups subjected to L1 gloss, L2 gloss, L1 and L2 gloss, and no gloss?

2). What preference do Saudi EFL learners have for glossed texts? 
3). What preference do Saudi EFL learners have for gloss types?

\subsection{Literature Review}

Previous studies brought mixed results regarding the effectiveness of glossing on learners reading comprehension. Some studies claim that there is a positive impact of glossing on reading comprehension, (e.g., Sakar \& Erçetin, 2005; Ko, 2012), while others prove the ineffectiveness of glossing on learners reading comprehension (Bell \& LeBlanc, 2000; H. Lee \& J. H. Lee, 2015; Jung, 2016). This distinction in the findings of the previous studies might be because of the different types of glossing techniques used by researchers. It is also important to note that the different purposes of examining glosses might create the diversity in the design of the previous studies and consequently the consistency in the previous studies findings. Various glossing conditions were used and compared, such as L1 versus L2 glosses (e.g. Ko, 2012), single versus multiple-choice glosses (e.g. Rott, 2005), multimedia versus textual glosses (e.g. Kost, Foss, \& Lenzini, 1999), and paper-based glosses vursus computerized glosses (e.g. Bowles, 2004), among others. Moreover, the degree of preciseness of the provided glosses also varies across the studies: a short definition or equivalent meaning of the word (e.g. Guidi, 2009), a blend of an interpretation and a relevant image or an illustrative video clip (e.g. Al-Seghayer, 2005), and a word definition and its use in a sentence (e.g. Hulstijn \& Laufer, 2001). It can be said that from the results from such studies on the influences of glosses on L2 reading comprehension were inadequate because of the different methodological approaches used on glossing.

Several studies have shown the ineffective impact of glossing on reading comprehension among learners. In the study of Bell and LeBlanc (2000) which examines the influence of using text glosses on participants reading comprehension, they find that glosses have no significant impact on students understanding. They find that there was no difference between L1 and L2 gloss regarding their influence on reading comprehension. Cheng and Good (2009) argue that no difference was reported regarding reading comprehension between gloss and no glosses. They also argue that the glosses in-text may distract the readers from reading. Chen and Yen (2013) state that the reading flow may possibly impede the reading comprehension when interrupting by the in-text glosses. Chun and Plass (1997) point to the negative impacts on learners' focus being split between the glosses and the text on reading comprehension. The study Tseng, Yeh, and Yang (2015), on the other hand, show that adding L1 glosses can support learners' comprehension by understanding the new words meaning. Morrison's (2004) asserts the important role of glosses in improving students' reading comprehension. Nation (1990) agrees that using glosses can assist reading comprehension. He adds that glossing can reduce the distraction that might occur by the interruption of checking new words in the dictionary. Sakar and Erçetin (2005) note that learners in their studies appreciated the assistive role played by the glosses as motivational and reading comprehension facilitator. Moreover, glosses allow students to get a chance to read abridged texts by providing meanings for a new vocabulary that are difficult to be successfully guessed (Nation, 2001). Davis (1989) states that glossing can lead to a positive effect on L2 reading comprehension. He finds that students with in-text glosses were significantly superior to those with no glosses. A similar result is found by Ko (2012) who notices that learners who read with glosses achieve better results than those with no glosses.

Regarding the distinction between the types of glossing, literature also shows inconsistent results and variations among previous studies were significant. Miyasako (2002) examined Japanese students with a purpose of understanding the success of L1 and L2 glosses. As such, 187 students were distributed in six respective groups. After reading a 504 worded text that had 20 glossed words, the respondents were subjected to another test several days later. The results indicated that the L2 groups outclassed the L1 group and that there was no significant difference between the two types of glosses. On the other hand, Ko (2012) conducted a study to establish how different types of gloss influenced the pattern of reading comprehension. In this case, Korean students were grouped into three groups, namely; (1) no gloss; (2) L1 gloss; and (3) L2 gloss. After taking the test where the ninety-four read a 277 worded text that had 25 glossed words, the results revealed that there was a significant difference between no gloss and L2 gloss group. Moreover, the L2 gloss had a superior mean to the L1 gloss group. The findings of the survey revealed that $62 \%$ of the interviewed respondents had a preference for L2 glosses while $32 \%$ preferred L1 glosses, and the rest preferring no gloss at all.

Thus, it is imperative to note the mixed results that the studies above have revealed the influence of L1 and L2 glosses on reading and comprehension by the learners. Previous studies also showed some distinctions in the most preferred type of glosses when reading texts. Studies that explored the Saudi contexts are not adequate. Therefore, the purpose of this study is to explore the influence of providing different types of glosses on tertiary Saudi university English majors' reading comprehension to read texts and acquire new vocabulary. Moreover, most of the previous studies reported the influence of the glossed types compared between L1 glossing, L2 glossing, and no glossing conditions. In this study, the combination of L1 and L2 glossing type is added to the 
comparison. Thus, four types of glossing will be included namely, L1 glossing, L2 glossing, L1 \& L2 glossing, and no glossing types.

\section{Method}

This study used the Pretest-Posttest Control-experimental group design using four groups of Qassim University male students. 72 EFL learners at Qassim University were divided into four groups randomly. Each group was assigned to read authentic texts under one of the following text conditions: L1 (Arabic) gloss, L2 (English) gloss, L1 and L2 (Arabic and English) gloss, and no gloss.

\subsection{Participants}

The study consisted of 72 Saudi English majors who aged between 19 and 21 years old. They were chosen from the eighth level in the English department at Qassim University, Saudi Arabia with criteria of Arabic language as their first language and English as their foreign language. Their proficiency level varied from intermediate to advance as estimated by their instructor. The instructor takes into consideration their performance in the Exit exam in the previous semester. Moreover, the selection of the participants was also based on the pre-test results to ensure that target words are not known to the students. The participants were administered with a pre-test to evaluate their knowledge and select them carefully to partake in the study. The test results indicated that the participants were not aware of the target words. Thus, it was assumed that these participants formed a homogeneous sample.

\subsection{Material and Design}

The reading material for this study was derived and retrieved from a passage of the 'More Reading Power.' The reading passage was selected from this book because it matched the advanced level of the learners in the study. The pre-test administered to the participants contained 30 items picked from the 505 -word text where they were to mention the meaning of the words they recognized and understood. After the test, 12 words were set aside as most participants had stated that they knew their meaning. The rest of the words were left glossed. The reading process was tested under four conditions; a text with no gloss, a test with L1 Arabic language glosses, a text with L2 English language glosses, a combination of with both the L1 and L2 gloss positioned alongside the glossed words. The study described three gloss groups and the no gloss group as experimental and control groups respectively.

\subsection{Data Collection Procedures}

This study followed previous related research (e.g., Bell \& LeBlanc, 2000; Xu, 2010; among others), in which the obtained data was collected and analyzed statistically to measure and compare the influence resulting from using various forms of glossed texts in experimental design. The experimental approach seemed appropriate for two reasons. First, using this method of data collection makes the findings of this study compared to previous research. Second, the results of this approach can allow for generalization across all groups of participating students. Moreover, the statistical analysis enabled identifications of causal effects and highlighted the correlation between the study variables.

Research subjects for this study were recruited using a random selection method and subsequently attached to one of the four groups differentiated into; L1 gloss, L2 gloss, a combination of L1 and L2, and the no gloss group. The learners in the study were subjected to a reading text test with the next exercise concerned with reading a comprehension test. The comprehension test consisted of ten English items evenly distributed amongst other kinds of text where the study group was required to choose the only correct answer. Lees's (1986) methods for the recall production of the L2 learners coding was adopted for all the reading passages. Hence, this study applied the rubrics with the reading texts to be employed in grading the recall protocols. Thus, in order to grade the recall protocols, a one-point scale rubric was used as a measurement instrument. The next test involved a questionnaire where the participants were required to point out which type of gloss they preferred. Lastly, they were further asked to write down what they recalled from the reading they had in L1.

\section{Data Analysis and Results}

\subsection{Influence of Different Types of Glosses on Reading Comprehension}

Data collected for this study were analyzed using the SPSS software utilizing both descriptive and inferential statistics. The use of ANOVA analysis to analyze the data with the significant level set at .05 revealed significant difference amongst the four groups tested. The study also utilized the method of Post Hoc Test to exhibit any existing relationships between the gloss types. 
Table 1. Descriptive statistics for reading comprehension among four research groups

\begin{tabular}{llll}
\hline & N & Mean & Std. Deviation \\
\hline No gloss & 18 & 13.01 & 5.31 \\
L1 Gloss & 18 & 24.97 & 15.17 \\
L2 Gloss & 18 & 23.06 & 9.81 \\
L1 and L2 Gloss & 18 & 25.72 & 10.22 \\
Total & 72 & 22.05 & 11.82 \\
\hline
\end{tabular}

In the table above, L1 and L2 gloss had a higher mean of 25.72 which indicates that the students read the text and gave more answers to the questions asked when compared to the other learners in the study. The L1 and L2 gloss group also had a standard deviation of 10.22. On the other hand, the no gloss group category had a mean and standard deviation of 13.01 and 5.31 respectively indicating that they answered very few questions when compared to the values achieved by participants in other groups. Otherwise, the L1 gloss group who read the text using the Arabic language scored a mean and a standard deviation of 24.97 and 15.17 respectively. The L2 gloss group consisting participants who read the text using the English language scored a mean and a standard deviation of 23.06 and 9.81 respectively. From the statistics, it is vital to note the standard deviations progressively showed the L1 gloss group with the highest dispersion followed by the combined L1 and L2 gloss group, L2 gloss group, and lastly, the control group in that order. It is certain that the control group had the same performance in the recall tests because of the insufficient textual glosses.

The case of the L1 and L2 gloss group and L1 gloss achieving high scores in the text comprehension may be attributed to various reasons. One reason may be because of the use of the mother tongue eased the learners in reading and recalling what they had read. Another reason may be directed towards the case of the Arabic language enhancing the learners' confidence to understand and remember the text they had been exposed from the gloss. The linkage of the L1 and L2 gloss could be another reason since it boasts vocabulary learning as learners have exposure to the first language and the target language that connects the vocabulary in the test. Nevertheless, the L2 gloss represented reduced rates, thus, indicating its ineffectiveness because English definitions are hard for the leaners taking EFL in their learning context to recall. Meanwhile, the case of the non-glossed texts proved difficult for the learners as they could not only recall them but also understand them. As such, this was pegged on the reason where no definition was given to learners' taking the tests. Concisely, the L1 and L2 gloss group is the most effective, with L1 gloss and L2 gloss, and lastly, the no gloss category summing up the groups tested.

Table 2. The results of One-way ANOVA for text comprehension

\begin{tabular}{llllll}
\hline & Sum of Squares & do & Mean Square & F & Sig \\
\hline Between & $1,875.94$ & 3 & 625.312 & 5.449 & 0.002 \\
Within & 7.803 .161 & 68 & 114.752 & & \\
Total & 9.679 .096 & 71 & & & \\
\hline
\end{tabular}

In the table above, the test results for text comprehension shows an F-value with a score of 5.449 which lies between and within scores of 3 and 68 respectively. Furthermore, the statistical significance is 0.002 which lies below the recommended scores of $\mathrm{p}<0.05$. The figures above indicate that the test on the independent variable ascertains that they are significant in their comparisons at a real probability.

Table 3. The Tukey post hoc multiple comparison tests

\begin{tabular}{|c|c|c|c|c|c|c|}
\hline (I) Group & (J) Group & Mean difference (I-J) & Std. Error & sig & $\begin{array}{l}\text { Lower } \\
\text { Bound }\end{array}$ & $\begin{array}{l}\text { Upper } \\
\text { Bound }\end{array}$ \\
\hline & L1 glossing & -11.96 & 3.78 & 0.0024 & -19.38 & -4.53 \\
\hline No glossing & L2 glossing & -10.05 & 2.62 & 0.0003 & -15.2 & -4.89 \\
\hline
\end{tabular}




\begin{tabular}{lllllll}
\hline \multirow{4}{*}{ L1 Glossing } & L1 \& L2 glossing & -12.71 & 2.71 & 0 & -18.01 & -7.38 \\
& No glossing & 11.96 & 3.78 & 0.0024 & 4.53 & 19.38 \\
& L2 glossing & 1.91 & 4.25 & 0.3288 & -6.43 & 10.25 \\
& L1 \& L2 glossing & -0.75 & 4.31 & 0.5687 & -9.2 & 7.7 \\
\multirow{3}{*}{ L2 Glossing } & No glossing & 10.05 & 2.62 & 0.0003 & 4.89 & 15.2 \\
& L1 glossing & -1.91 & 4.25 & 0.9593 & -10.25 & 6.43 \\
& L1 \& L2 glossing & -2.66 & 3.33 & 0.7842 & -9.2 & 3.88 \\
L1 \& L2 glossing & No glossing & 12.71 & 2.71 & 0 & 7.38 & 18.03 \\
& L1 glossing & 0.75 & 4.31 & 0.431 & -7.7 & 9.2 \\
& L2 glossing & 2.66 & 3.39 & 0.215 & -3.88 & 9.2 \\
\hline
\end{tabular}

Table 3 indicates that the Turkey post hoc multiple comparison tests conducted on the gloss groups regarding the reading comprehension resulted in the following differences significantly:

1) The L1 gloss group compared with other groups shows No glossing ( $M=11.96, S D=3.78)$, L2 glossing $(\mathrm{M}=1.91, \mathrm{SD}=4.25)$ and, $\mathrm{L} 1 \& \mathrm{~L} 2$ glossing as $(\mathrm{M}=-0.75, \mathrm{SD}=3.78)$.

2) The L1 and L2 gloss group compared to the other groups shows No glossing ( $M=12.71, \mathrm{SD}=2.71), \mathrm{L} 1$ glossing $(\mathrm{M}=0.75, \mathrm{SD}=4.31)$ and, $\mathrm{L} 2$ glossing as $(\mathrm{M}=2.66, \mathrm{SD}=3.39)$.

3) The $\mathrm{L} 2$ gloss group compared to other groups No glossing $(\mathrm{M}=10.05, \mathrm{SD}=2.62), \mathrm{L} 1$ glossing $(\mathrm{M}=-1.91$, $\mathrm{SD}=4.25)$ and, $\mathrm{L} 1 \& \mathrm{~L} 2$ glossing as $(\mathrm{M}=-2.66, \mathrm{SD}=3.33)$.

As such, the results from the test above indicates that the learners in the experimental groups scored higher than those in the control group through comparisons effected on their variables. The significant difference was noted in the reading comprehension from the scores of the leaners in the no gloss group when compared to those in the experimental group. However, there was no significant difference between reading comprehension mean scores of learners in the active gloss groups namely; L1, L2, combined L1 and L2 gloss groups.

Table 4. Means and standard deviation of recalled ideas

\begin{tabular}{llll}
\hline Condition & $\mathrm{N}$ & Mean & Std. Dev \\
\hline No gloss & 18 & 4.7 & 2.29 \\
L1 Gloss & 18 & 12.53 & 5.12 \\
L2 Gloss & 18 & 9.83 & 4.23 \\
L1 and L2 Gloss & 18 & 1.89 & 0.78 \\
\hline
\end{tabular}

The results presented in Table 4 are similar to those in Table 1. The results indicate that learners who read the text in L1 gloss (Arabic language) recalled more ideas than learners in the other groups. This gloss group was followed subsequently by the L1 and L2 gloss group in the recall of ideas. The no gloss group ranked last in this category of recalling ideas.

Table 5. Analysis of variance of number of recalled ideas

\begin{tabular}{llllll}
\hline & Sum of Squares & Do & Mean Square & F & Sig \\
\hline Between & 1567.98 & 3 & 522.66 & 9.71 & 0 \\
Within & 3603.45 & 68 & 53.78 & & \\
Total & 5171.43 & 71 & & & \\
\hline
\end{tabular}

The results in Table 5 above show the scores of F-value at 9.71 with the statistical significant reading .000 which indicates significant differences amongst the groups in the study. 


\subsection{Participants' Preference for Glossed or Non-Glossed Texts}

Table 6 represents results on the research question that sought whether tertiary EFL learners had a preference to read glossed texts or non-glossed texts derived through the questionnaire.

Table 6. Participants' preference percentage for reading texts

\begin{tabular}{ll}
\hline Prefer to read glossed text & $93.05 \%$ \\
\hline Prefer to read non-glossed texts & $6.95 \%$ \\
\hline
\end{tabular}

The results in the table above indicate that $93.05 \%$ of the 72 learners preferred to read glossed texts with the rest $6.95 \%$ opting to read non-glossed texts. These results could imply that many students are often challenged with the uncertainty of unknown words, thus, the need to have textual enhancement purposely to comprehend the given text. These results indicate that textual glosses are essential in assisting learners to the reading comprehension passages.

\subsection{The Comparison of Gloss Preferences among Four Research Groups}

The table below represents results of the learners when asked the question whether they had different preferences on gloss types. The results were tested on one item in post-reading and asked through the questionnaire.

Table 7. Gloss preferences percentage among glossed text groups

\begin{tabular}{lll}
\hline Gloss type & No & Percentage \\
\hline L1 \& 12 (Arabic and English) & 41 & 56.94 \\
L1 (Arabic) Gloss & 17 & 23.61 \\
L2 (English) gloss & 9 & 12.5 \\
\hline
\end{tabular}

Results in Table 7 above show the differences in the responses given by learners in the slated gloss groups. Furthermore, the results in Table 6 are relevant and link in the explanation of these results found in Table 7. Amongst the $93.05 \%$ of the learners who indicated that they preferred to read glossed texts, further results show that $56.94 \%$ desired to read the L1 and L2 glosses, $23.61 \%$ had a preference for having L1 gloss, and $12.5 \%$ favored the L2 glosses. These results can be summarized with L1 and L2 glosses encouraging reading comprehension followed by L1 gloss and L2 gloss respectively.

In this case, learners preferred to read glossed tests with most of them favoring L1 and L2 glossed texts, followed by L1 glossed texts and L2 glossed texts respectively. Furthermore, the learners seem to lack vocabulary knowledge hence the need for vocabulary glossing to aid them to comprehend reading the passages.

\section{Discussion}

The responses to the research question posed to the respondents in this study aimed to explore whether the provision of different textual glosses would result in more answers in favor of L2 reading comprehension. Nevertheless, the results showed that the learners in the L1 gloss, L2 gloss and the combined L1 and L2 gloss groups achieved higher scores when compared to those in the control group regarding reading comprehension. This finding is similar to the findings in the previous studies conducted by Ko (2012), Tseng, Yeh, and Yang, (2015) that confirmed the relevance of vocabulary glossing in aiding learners through reading comprehension effectively.

The other findings in this study also highlighted numerous benefits of the textual glosses when compared to the no gloss type. As such, it was manifested that learners process the L1 glossed text faster than the no glossed text as evidenced by the model of the lexical and conceptual representation pursued by Kroll and Stewart (1994). Accordingly, the Kroll and Stewart's model provides the connection and conceptual link that is stronger between the L1 and L2 concepts. Moreover, the firm relationship is attributed to the assumption of the L2 words association with those of L1 (Kroll \& Stewart, 1994). In this regard, the L1 can effectively aid and function as a lexical intermediary between L2 and the respective conceptual meanings (Haritos \& Nelson, 2001). Based on these findings, the results of this study are anticipated given that the students are supposedly placed in a low 
achievers' category. Additionally, Ko (2012) stipulates that L2 glosses can be more beneficial to learners than L1 if their proficiency in linguistics is high.

In another research question dwelt on the learners' preferences on their views regarding glossed and no glossed text. Results from this study indicate that most of the students had a high preference of $93.05 \%$ favoring the glossed texts against the non-glossed ones. These findings confirm the findings from previous studies carried out by Sakar \& Erçetin (2005), and Ko (2012). In this regard, it is inevitable to note that lack of vocabulary can pose a challenge for learners and scholars pursuing a second language. Similarly, Grabe (1991) points out that vocabulary is the link that can either enhance or deter comprehension, hence, the need for glossed text to aid and facilitate understanding among learners. Succinctly, this finding proves the reason why most learners in this study had a high preference for glossed texts over non-glossed texts.

In the study, another question on the preference for textual glosses was administered to the students. The results of the study indicated that $56.94 \%$ of the learners preferred to have L1 and L2 glosses, with $23.61 \%$ favoring the $\mathrm{L} 1$ glosses, and $12.5 \%$ opting for the L2 glosses. This finding correlates with the result from the study conducted by Bell and LeBlanc (2000) where most students voiced their preference in L1 and L2 with the English gloss group and the Spanish gloss group manifesting similar characteristics, for example, number of times they clicked on words. However, this finding contradicts the results and findings reported from other studies conducted by Ko (2012), Jacobs, Dufon and Hong (1994).

\section{Conclusion}

This study explored the underlying impact of different types of glosses on students studying English as a foreign language. The study involved grouping the glosses into L1 (Arabic language), L2 (English language), a combination of L1 and L2, and lastly the no gloss category that tested reading comprehension. Results from the study where the learners were subjected to reading a chosen English word under the four gloss conditioned categories revealed differences in the recall process of ideas amongst the groups. As such, students in the gloss groups had higher scores of recalling more ideas than those in the no gloss group. Moreover, it was found out that students had a preference for the use of L1 and L2 glossed texts over the L1, and L2 glossed text. It was further indicated that there was no statistical significance amongst the groups.

Nevertheless, despite the progress manifested by the findings of this study, there are some implications reported that associate with reading comprehension. A major aspect was that the gloss and no conditions were significantly distinct. On the one hand, the presence and accessibility of textual gloss may implicate students to save time from not searching for unknown words in the dictionary. This tendency can enhance the reading process and enable learners to comprehend texts with ease and timely. Furthermore, this may elicit a suggestion on the adoption of the use of glossed text in the curriculum to boost reading comprehension amongst learners. On the other hand, teachers of reading comprehension courses should be encouraged to adopt such strategies that enable L2 learners to enhance their reading comprehension process.

Whereas this study used only one passage for the reading test, future studies should aim at more tests to provide results with broader findings. Furthermore, future studies can embrace diverse locations to avoid the risk of influence on vocabulary learning and reading comprehension. In addition to the inclusion of students with varied proficiencies, it is suggested that future studies also include female Saudi Arabian learners to provide expansive and quality findings.

\section{References}

Ali, Z., \& Ayub, A. F. (2012). Obstacles and Successes in Learning Vocabulary from Context. Paper presented at Graduate Research in Education Seminar (GREduc2012).

Al-Seghayer, K. (2005). The effect of multimedia annotation modes on L2 vocabulary acquisition. Research in technology and second language education: Developments and directions, 3, 133.

Bell, F. L., \& LeBlanc, L. B. (2000). The language of glosses in L2 reading on computer: Learners' preferences. Hispania, 83(2), 274-285. https://doi.org/10.2307/346199

Bowles, M. A. (2004). L2 glossing: To CALL or not to CALL. Hispania, 541-552. https://doi.org/10.2307/20063060

Chen, H. (2002). Investigating the effects of L1 and L2 glosses on foreign language reading comprehension and vocabulary retention. Paper presented at the annual meeting of the Computer-Assisted Language Instruction Consortium, Davis, CA. 
Chen, I. J., \& Yen, J. C. (2013). Hypertext annotation: Effects of presentation formats and learner proficiency on reading comprehension and vocabulary learning in foreign languages. Computers \& Education, 63, 416-423. https://doi.org/10.1016/j.compedu.2013.01.005

Cheng Y., \& Good, R. L. (2009). L1 glosses: Effects on EFL learners' reading comprehension and vocabulary retention. Reading in a Foreign Language, 21(2), 119-142.

Davis, J. N. (1989). Facilitating effects of marginal glosses on foreign language reading. The Modern Language Journal, 73(1), 41-48. https://doi.org/10.1111/j.1540-4781.1989.tb05308.x

Grabe, W. (1991). Currents developments in second language reading research. TESOL Quarterly, 25(3), 375-406. https://doi.org/10.2307/3586977

Guidi, C. (2009). Glossing for meaning and glossing for form: A computerized study of the effects of glossing and type of linguistic item on reading comprehension, noticing, and L2 learning. Unpublished $\mathrm{PhD}$ dissertation, Georgetown University, Washington, DC, USA

Harites, C., \& Nelson, K. (2001). Bilingual memory: the interaction of language and thought. Bilingual Research Journal, 24(4), 417-438. https://doi.org/10.1080/15235882.2001.11074469

Hulstijn, J. H., \& Laufer, B. (2001). Some empirical evidence for the involvement load hypothesis in vocabulary acquisition. Language Learning, 51, 539-558. https://doi.org/10.1111/0023-8333.00164

Jacobs, G. M., Dufon, P., \& Hong C. F. (1994). L1 and L2 vocabulary glosses in L2 reading passages: their effectiveness for increasing comprehension and vocabulary knowledge. Journal of Research in Reading 17, 19-28. https://doi.org/10.1111/j.1467-9817.1994.tb00049.x

Jung, J. (2016). Effects of glosses on learning of L2 grammar and vocabulary. Language Teaching Research, 20(1), 92-112. https://doi.org/10.1177/1362168815571151

Ko, M. H. (2012). Glossing and second language vocabulary learning. TESOL Quarterly, 46(1), 56-79. https://doi.org/10.1002/tesq.3

Kroll, J. F., \& Stewart, E. (1994). Category interference in translation and picture naming: Evidence for asymmetric connections between bilingual memory representations. Journal of Memory and Language, 33, 149-174. https://doi.org/10.1006/jmla.1994.1008

Kost, C. R., Foss, P., \& Lenzini, J. J. (1999). Textual and pictorial glosses: Effectiveness on incidental vocabulary growth when reading in a foreign language. Foreign Language Annals, 32(1), 89-97. https://doi.org/10.1111/j.1944-9720.1999.tb02378.x

Lee, J. F. (1986). On the use of the recall task to measure L2 reading comprehension. Studies in second language acquisition, 8(2), 201-211. https://doi.org/10.1017/S0272263100006082

Lee, H., \& Lee, J. H. (2015). The effects of electronic glossing types on foreign language vocabulary learning: Different types of format and glossary information. The Asia-Pacific Education Researcher, 24(4), 591-601. https://doi.org/10.1007/s40299-014-0204-3

Miyasako, N. (2002). Does text-glossing have any effects on incidental vocabulary learning through reading for Japanese senior high school students? Language Education \& Technology, 39, 1-20.

Morrison, J. T. (2004). Reducing the cognitive load presented by definition presentation in electronic learning environments through the use of hypermedia rollovers. Florida, USA: Unpublished doctoral dissertation, University of Central Florida

Nagy, W. E. (1988). Teaching vocabulary to improve reading comprehension. Newark, DE: International Reading Association.

Nation, I. S. P. (1990).Teaching and learning vocabulary. Boston, Mass.: Heinle \& Heinle.

Nation, I. S. (2001). Learning vocabulary in another language. Cambridge: Cambridge University Press. https://doi.org/10.1017/CBO9781139524759

Palmer, J., Boon, R. T., \& Spencer, V. G. (2014). Effects of concept mapping instruction on the vocabulary acquisition skills of seventh-graders with mild disabilities: A replication study. Reading \& Writing Quarterly, 30(2), 165-182. https://doi.org/10.1080/10573569.2013.818890

Rott, S. (2005). Processing glosses: A qualitative exploration of how form-meaning connections are established and strengthened. Reading in a Foreign Language, 17(2), 95. 
Sakar, A., \& Ercetin, G. (2005). Effectiveness of hypermedia annotations for foreign language reading. Journal of Computer Assisted Learning, 21(1), 28-38. https://doi.org/10.1111/j.1365-2729.2005.00108.x

Taylor, A. M. (2002). A Meta-Analysis on the Effects of L1 Glosses on L2 Reading Comprehension. Unpublished doctoral dissertation, Purdue University, Indiana.

Tseng, S. S., Yeh, H. C., \& Yang, S. H. (2015). Promoting different reading comprehension levels through online annotations. Computer Assisted Language Learning, 28(1), 41-57. https://doi.org/10.1080/09588221.2014.927366

$\mathrm{Xu}, \mathrm{X}$. (2010). The effects of glosses on incidental vocabulary acquisition in reading. Journal of language teaching and research, 1, 117-120. https://doi.org/10.4304/jltr.1.2.117-120

Yoshii, M. (2006). L1 and L2 glosses: their effects on incidental vocabulary learning. Language Learning \& Technology, 10(3), 85-101.

\section{Copyrights}

Copyright for this article is retained by the author(s), with first publication rights granted to the journal.

This is an open-access article distributed under the terms and conditions of the Creative Commons Attribution license (http://creativecommons.org/licenses/by/4.0/). 